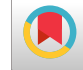

\title{
Burn Injury of a Pregnant Mother in Rural Bangladesh: A Case Report
}

\author{
Animesh Biswas, ${ }^{1,{ }^{*}}$ Koustuv Dalal, ${ }^{2}$ Toity Deave, ${ }^{3}$ and Saidur Rahman Mashreky ${ }^{1,4}$ \\ ${ }^{1}$ Centre for Injury Prevention and Research Bangladesh (CIPRB), Dhaka, Bangladesh \\ ${ }^{2}$ Centre for Injury Prevention and Safety Promotion, School of Health Sciences, Orebro University, Sweden \\ ${ }^{3}$ University of the West of England, Bristol, United Kingdom \\ ${ }^{4}$ Bangladesh University of Health Sciences (BUHS), Bangladesh \\ "Corresponding author: Dr Animesh Biswas, PhD, Centre for Injury Prevention and Research Bangladesh (CIPRB), House B-162; Road 23, New DOHS Mohakhali, Dhaka, \\ Bangladesh, E-mail: ani72001@gmail.com
}

Received 2016 October 18; Revised 2016 December 22; Accepted 2017 January 09.

\begin{abstract}
Introduction: This paper describes a case of pregnant mother who died of burn injury in order to understand the societal factors related to the event. We reviewed the case in the rural community. Initially, the case was reported as a maternal death to maternal and neonatal death review (MNDR) system being conducted in Bangladesh within exiting health system to explore the medical and social causes of maternal and newborn deaths. However, during the verbal autopsy, it was found that the mother died of bun injury. Therefore, we performed detailed case study.

Case Presentation: A woman aged 18 years was nine months pregnant in a rural community in Moheskhali upazila of Cox's Bazar district. During the wintertime, the mother feels cold and goes near to the oven in the yard to be warm. Suddenly, part of her clothing (Anchal of Sari) catches fire; she does not recognized and starts to walk towards her room. A neighbor notices and starts to shout. The woman scars and tries to run. The neighbors come with a bucket of water. By this time, the fire spreads over whole body and cloths. Immediately after the event, she is transferred to a medical college hospital.

Conclusions: Doctors tried to do immediate cesarean section; however, they could not save the life of the baby inside. The mother who was severely burnt also died after 10 days. Rural community in Bangladesh still does not have adequate awareness and knowledge about risk of burn. The scarce knowledge of appropriate steps immediately after burn was explored. Moreover, delays in decision-making and transferring the patient to the facility were identified. Specific interventions need to be taken to increase knowledge and awareness in the community, which could save thousands of lives.
\end{abstract}

Keywords: Burn Injury, Pregnancy, Prevention, Bangladesh

\section{Introduction}

Burns are devastating injuries and cause significant mortality and morbidity globally (1). In the south East Asian regions, India, Pakistan, Nepal, Sri Lanka, and Afghanistan, burn injuries have emerged as a major public health issue (2). In Bangladesh, more than 5000 people die every year and the rate of burn injuries was found to be higher amongst females (3). Most unintentional burns occur in the home around the cooking area, with flames being the major cause (4). Women of reproductive age are often victims of burn injury in developing countries (5). Burns that occur during pregnancy are uncommon; however, these injuries are often fatal for both the pregnant mother and her fetus, especially in low-income countries (5-9). Mortality and morbidity due to severe burn injury are significantly higher among pregnant women than in the general population considering the same degree of injury. Studies have investigated the outcome of the burnt mother in hospital settings considering the total body area of burn and treatment (10). Burn during pregnancy not only makes treatment for the mother difficult but also puts the fetus in danger. Experts have advocated for more studies concerning pregnant women with severe burn injury. Existing literature is mainly from high-income countries. There is dearth of literature on low-income countries where the burden of burn during pregnancy is higher (59). A case study is the 'study of a phenomenon' where one actor/person is involved (11). This paper describes a case of an adolescent pregnant mother who caught fire and burnt during late pregnancy. Also, neighbors' and family members' opinions about this burn case were discussed.

\section{Case Presentation}

The mother was 18 years old from a poor family with low socio-economic context. The monthly income of the family was below 25 dollars in a month. Her husband was 
an angler. She lived in one of the remotest costal belt area of Cox's Bazar district named Moheskhali. It was her first pregnancy and she was nine months pregnant. The mother was living with her mother-in-law in a mud built house. The mother had to do all the housework despite being pregnant. Her mother-in-law was too old to do regular household work. It was the winter season. After completing her daily work in the afternoon, the mother feels so cold. She goes to get warm from the fire in the yard. It is about $5 \mathrm{pm}$ in the evening. Suddenly, part of her clothing (saree) gets on fire. Unfortunately, she does not understand what is happening. The fire catches her saree and starts to spread. One of the neighbors sees the mother and starts to shout. Once she realizes what is happening, the mother scares and starts to run; but the fire spreads to the whole body. The villagers bring buckets of water and try to stop the fire. A neighbor uses a handmade fan to cool the burnt area but it is too late to stop the fire. According to the statement of her family members, the whole of the mother's body is burnt, especially her back.

Her husband was not at home when it happened and when he returned he was unable to decide what was needed to done. Time was passing and the mother was still screaming. It took two hours to decide to take her to the government primary health care center at upazila. Then, the mother was transferred by boat to the health center, which took an extra hour. At the health care centre (primary care center), the duty doctor immediately visited the mother and referred her to the district hospital since there was no facility to treat a severe burn patient. The district hospital (secondary health care centre) was 24 miles away from the upazila health care centre. Several hours later, the mother was admitted to the district hospital. The doctors at the district hospital decided to undertake cesarean section to deliver the baby. Unfortunately, because of the burn injury, it was a stillbirth. The baby had a number of blackish scars on the skin and the doctors suspected they might have been due to the burn injury.

According to the family, the mother had more than fifty percent total body surface burn. The mother survived for another 14 days but finally died.

Two experienced researchers along with health care providers had a brief discussion with the family members and neighbors. They (later) highlighted that they did not have any idea about immediate first aid following a burn. They also discussed the fact that the mother was unaware of the possibility of saree catching fire during winter as well as not knowing what should be done if her saree and/or clothing catch fire. One of the neighbors mentioned that the community has misperception on things to do immediately after burn. Using substances like toothpaste, egg, mud, and salt in burnt area is still common and widely practiced. The neighbors also mentioned the lack of knowledge about fire prevention and treatment of burns. Moreover, this deprived community lives in a hardto-reach costal belt of the country and has high illiteracy rates. These all are factors that may lead to higher rates of burn injuries.

\subsection{Ethical Issue}

The study has received ethical permission from the institutional review board of the centre for injury prevention and research, Bangladesh. Researchers had strictly followed all ethical guidelines provided by Helsinki declaration.

\section{Discussion}

Every maternal death is tragic. In this case, the mother died of a burn injury; therefore, it is classified as an injury death rather a maternal death due to maternal complications (12-14). It was revealed that the mother caught fire in her "saree" during winter season when warming herself by the fire in the courtyard, a known risk factor (15). In India, $50.6 \%$ of women who suffered flame burns were found to be wearing traditional saree (15). This case study took place in Bangladesh where seasonal variations in fire-related and burn injuries occur, with winter being the most common season because of exposure of saree or winter cloths to open flame, cooking fire, traditional kerosene lamp, even to heating fire (4). One study in Iran reported flame burns to be more frequent (66.7\%) than scalds (10.2\%) in pregnant women (9).

In this study, we found that community knowledge and practice about burn prevention and first aid were poor. The villagers were unaware about what to do when a person catches fire. The mother started running as soon as she saw that the fire was burning her saree and there was a delay in deciding to take her to hospital. In Bangladesh, the community's response when a resident was burnt was incorrect and this led to the death of the person (16). Overall hospital admission due to burn injury in Bangladesh is 12.6 per 100,000 population-year (17), with female admissions being higher than male admissions (1). In this study, the family delayed in decision-making and therefore the mother's transfer to hospital was delayed by many hours. In developing countries, delay in decision-making, delay in transferring mother with complications, and delay in providing timely treatment are of contributing factors to maternal deaths (18). Here, it was a burn case and the delay resulted in maternal death. The doctors tried to save the baby's life by undertaking an emergency cesarean section but the outcome was, unfortunately, a stillbirth. Early caesarian section is indicated in the case of a mother in her 
third trimester when she experiences an extensive burn injury, with fetal survival highly dependent on maternal survival; ex-utero survival is poor (19). In Nigeria, $71 \%$ of the patients with extensive burn injury had stillbirth (20).

The main predictor of the survival of pregnant woman is the percentage of total body surface area affected (5). In most cases in which both the mother and the fetus died, the total body surface area was more than $40 \%(5,7,8,10$, 21).

In a low-income country like Bangladesh, there is still a lack of knowledge and poor practice on burn injuries. In rural settings, people perceive a burn injury as God's will, which often affects their health seeking behavior, leading to poor burn patient management $(16,22)$. In this case, we clearly demonstrated that only correct knowledge and awareness of actions could help both mother and baby survive. Although a number of initiatives already has been taken by the government to reduce the maternal and neonatal deaths in Bangladesh $(23,24)$, it is important to broaden the focus on other contributing factors that may lead to the death of mother and baby due to, for example, a burn injury. Increasing community awareness and improving knowledge through education and mass media are two methods by which we can disseminate correct messages to help prevent such deaths in future.

\subsection{Conclusions}

Burn injuries that occur during pregnancy are preventable. Lack of and/or incorrect knowledge about safety and what actions to take following a burn injury may lead to fatal consequences for women during pregnancy. To prevent these devastating injuries in a rural community, particular attention needs to pay to improve a community's and families' knowledge and practice. Educational programs could be effective in increasing the knowledge of rural communities. Community awareness of immediate first-aid actions that reduce the depth and extent of burn injuries could be effective.

\section{Footnote}

Funding/Support: There was no funding from any organization, except for salaries from universities/institution.

\section{References}

1. Mashreky SR, Rahman A, Chowdhury SM, Giashuddin S, Svanstrom L, Khan TF, et al. Burn injury: economic and social impact on a family. Public Health. 2008;122(12):1418-24. doi: 10.1016/j.puhe.2008.06.007. [PubMed: 18718620].
2. Mashreky SR, Rahman A, Khan TF, Svanstrom L, Rahman F. Determinants of childhood burns in rural Bangladesh: A nested case-control study. Health Policy. 2010;96(3):226-30. doi: 10.1016/j.healthpol.2010.02.004. [PubMed: 20202714].

3. Mashreky SR, Rahman F, Rahman A, Baset KU, Biswas A, Hossain J. Burn injury in Bangladesh: electrical injury a major contributor. Int J Burns Trauma. 2011;1(1):62-7. [PubMed: 22928160].

4. Mashreky SR, Rahman A, Svanstrom L, Khan TF, Rahman F. Burn mortality in Bangladesh: findings of national health and injury survey. Injury. 2011;42(5):507-10. doi: 10.1016/j.injury.2009.11.020. [PubMed: 20031124].

5. Karimi H, Momeni M, Momeni M, Rahbar H. Burn injuries during pregnancy in Iran. Int J Gynaecol Obstet. 2009;104(2):132-4. doi: 10.1016/j.ijgo.2008.10.003. [PubMed: 19022440].

6. Mabrouk AR, el-Feky AE. Burns during pregnancy: A gloomy outcome. Burns. 1997;23(7-8):596-600.

7. Akhtar MA, Mulawkar PM, Kulkarni HR. Burns in pregnancy: Effect on maternal and fetal outcomes. Burns. 1994;20(4):351-5.

8. Maghsoudi H, Samnia R, Garadaghi A, Kianvar H. Burns in pregnancy. Burns. 2006;32(2):246-50. doi: 10.1016/j.burns.2005.10.003. [PubMed: 16448763].

9. Pasalar M, Mohammadi AA, Rajaeefard A, Neghab M, Tolidie HR, Mehrabani D. Epidemiology of burns during pregnancy in southern Iran: Effect on maternal and fetal outcomes. World Appl Sci J. 2013;28(2):153-8.

10. Shi Y, Zhang X, Huang BG, Wang WK, Liu Y. Severe burn injury in late pregnancy: a case report and literature review. Burns Trauma. 2015;3:2. doi: 10.1186/s41038-015-0002-z. [PubMed: 27574648].

11. Swanborn P. Caase study research: What, why and how? London: Sage Publications Ltd; 2010.

12. World Health Organization . Maternal death surveillance and response: Technical guidance, information for action to prevent maternal death. Bull World Health; 2013.

13. Say L, Chou D, Gemmill A, Tuncalp O, Moller AB, Daniels J, et al. Global causes of maternal death: A WHO systematic analysis. Lancet Glob Health. 2014;2(6):323-33.

14. WHO UUTWBATUNPD. Trends in maternal mortality: 1990 to 2013. Geneva, Switzerland: World Heal Organ; 2014.

15. Golshan A, Patel C, Hyder AA. A systematic review of the epidemiology of unintentional burn injuries in South Asia. J Public Health (Oxf). 2013;35(3):384-96. doi: 10.1093/pubmed/fds102. [PubMed: 23321681].

16. Mashreky SR, Rahman A, Chowdhury SM, Svanstrom L, Shafinaz $S$, Khan TF, et al. Health seeking behaviour of parents of burned children in Bangladesh is related to family socioeconomics. Injury. 2010;41(5):528-32. doi: 10.1016/j.injury.2009.05.017. [PubMed: 19539286].

17. Mashreky SR, Rahman A, Chowdhury SM, Khan TF, Svanstrom L, Rahman F. Non-fatal burn is a major cause of illness: findings from the largest community-based national survey in Bangladesh. Inj Prev. 2009;15(6):397-402. doi: 10.1136/ip.2009.022343. [PubMed: 19959732].

18. Halim A, Utz B, Biswas A, Rahman F, van den Broek N. Cause of and contributing factors to maternal deaths; a cross-sectional study using verbal autopsy in four districts in Bangladesh. BJOG. 2014;121 Suppl 4:86-94. doi: 10.1111/1471-0528.13010. [PubMed: 25236640].

19. Guo SS, Greenspoon JS, Kahn AM. Management of burn injuries during pregnancy. Burns. 2001;27(4):394-7.

20. Chama CM, Na'Aya HU. Severe burn injury in pregnancy in Northern Nigeria. J Obstet Gynaecol. 2002;22(1):20-2. doi: 10.1080/01443610120101646. [PubMed: 12521721].

21. Jain ML, Garg AK. Burns with pregnancy: A review of 25 cases. Burns. 1993;19(2):166-7.

22. Mashreky SR, Rahman A, Chowdhury SM, Svanstrom L, Linnan M, Shafinaz S, et al. Perceptions of rural people about childhood burns and their prevention: a basis for developing a childhood burn prevention programme in Bangladesh. Public Health. 2009;123(8):568-72. doi: 10.1016/j.puhe.2009.06.014. [PubMed: 19665740]. 
23. Biswas A, Rahman F, Eriksson C, Dalal K. Community notification of maternal, neonatal deaths and still births in maternal and neonatal death review (MNDR) system: Experiences in Bangladesh. Health. 2014(September):2218-26.
24. Biswas A, Rahman F, Halim A, Eriksson C, Dalal K. Maternal and neonatal death review (MNDR) : A useful approach to identifying appropriate and effective maternal and neonatal health initiatives in Bangladesh. Health. 2014(July):1669-79. 